The Paradox of the Piano Player.

WHEN a number of notes in different parts of the keyboard of a pianoforte are struck by means of levers actuated by a common pneumatic pressure, it appears to be the universally prevailing belief that the only variations possible are those in which the whole chord is made to sound louder or softer by increasing or decreasing the pressure. It is commonly regarded as an impossibility to vary the relalive intensities of the sounds produced by the various notes so as to make, e.g., the bass parts sound louder and the treble softer, or vice versî.

On the other hand, dynamical considerations suggest that the intensities of the sounds excited in the different strings of the piano depend, not only on the total pressure applied to the mechanism, but also on the way in which this pressure is made to vary during at least part of the interval from the instant at which the key is first touched to the instant at which the hammer leaves the strings. A short, sharp impulse suddenly cut off should produce its greatest effect on the notes of higher pitch, while a heavy, sustained or increasing pressure should make its effect most marked on the lower notes of the instrument. During the last few months, I have given considerable attention to the practical application of this theory, and the effects which I find it possible to produce, provided that the accentuation is performed at exactly the right instant of time, are moit remarkable. The treble or bass parts may be made to stand out in so conspicuous a way as to make it difficult to believe that different notes of the chords are not struck by different human fingers. The matter opens up a wide field of discussion, and suggests considerable possibilities in the way of quantitative laboratory measurements. For the present, it may be sufficient to suggest that those of your readers who possess the new musical instruments of the twentieth century suitable for the purpose should, if they have not already done so, perform the experiment for themselves; they will soon be rewarded by being able to enjoy their music in a way they have never enjoyed it previously. $\quad$ G. H. BRYAN.

\section{Cost of Scientific Education in Germany and England.}

I NOTICE, in the issue of NATURE of December 4, that you quote Mr. Holzapfel's letter to the Times on the cost of scientific education in Germany and England. Although, unfortunately, there can be no dispute as to the great difference between the fees charged in Germany and in England, I think it right that the fees of King's College should be correctly stated. The sum quoted by $\mathrm{Mr}$. Holzapfel represents the charge made for chemistry and physics; for chemistry only it was $34 l .18$ s. for the year. I have no knowledge of the amount of instruction which the other son obtained for $7 l$. at Aachen.

King's College, London, W.C., December 9.

\section{THE REPRODUCTION OF COLOURS BY PHOTOGRAPHY.}

THE services which photography has rendered to science are now well recognised, and its value for urposes both of observation and record is well known and admitted. It is probably not so well known that methods now exist by which not only the form, but the colour, of natural objects can be represented with approximate fidelity. We are fortunate in being able to illustrate this fact by a plate giving some excellent reproductions of birds' eggs, produced under the superintendence of Mr. H. E. Dresser, entirely by photographic methods, and without the intervention of an artist.

There is no need to dwell on the value of such work. For many scientific purposes it is as important to record colour as shape, and if this can be done in a trustworthy manner, a new and useful power is placed at the disposal of the teacher of science and of the writer of scientific books. The difficulty about the three-colour process of photography is that it is extremely difficult to make certain that the colours are reproduced with sufficient accuracy for scientific work. Accuracy enough for pictorial purposes is easily attained, but

NO. 1728 , vOL. 67$]$ absolute truth to nature is quite another thing. The reasons for this are various. The photographic gradation of light intensities, in the case of both white light and of its various components, is generally different from the visual gradation, and even if accuracy is ensured in a narrow range of tones, it is hardly possible to make certain of its being secured in wider ranges: Another difficulty is that pigments have to be employed, and such pigments can never, of course, give pure colours. The consequence of this is that in the production of the picture it is necessary to vary the intensity of the different colouring agents employed until a satisfactory result is obtained. There is thus considerable room for judgment and dexterity, and the final result is not automatic, but depends on the artistic skill of the person who produces the picture. The whole process is, it must be admitted, of the character of a makeshift, but at the same time, when carefully employed it is a makeshift of considerable practical use.

Mr. Dresser, in the article printed below, deals only with the representation of natural objects for purposes of book illustration. An equally valuable application of the process is for the production of lantern slides for purposes of demonstration, and, as many of our readers are well aware, the process is beginning to be largely used for such purposes. A lantern slide coloured by hand is at best but a poor thing, and though a few very skilful operators-such as Mr. Cyril Davenport, of the British Museum - have by a combination of microscopic sight and great deftness of manipulation succeeded in producing some remarkable results, even these will hardly stand the large amount of magnification required by the lantern. Now a slide made by the three-colour process will stand as much enlarging as any ordinary photographic slide, and will give a reasonably close approximation to the natural colours of the subject. The process is applicable to any specimen which can be photographed. Excellent reproductions of microscopic objects have thus been produced; botanical specimens, birds, beetles and butterflies have all been rendered with great beauty and with really close accuracy to nature. Those who were present at Prof. Poulton's lectures at the Royal Institution last session had the opportunity of admiring the exquisitely coloured pictures he showed of insects, all produced by the process, which, first practically demonstrated by Mr. F. E. Ives, has since been further developed by Mr. Sanger Shepherd and others in this country.

Although, as said above, absolute accuracy is very difficult, or even impossible, to ensure-certainly not by automatic means-it is not too much to say that any photographer ought, after a very little practice, to be able to produce useful and serviceable illustrations for lecture purposes if he is content with something which, though not perhaps the best possible, is infinitely superior to anything which can be produced by painting an ordinary monochrome lantern slide.

Mr. Dresser in his remarks places, perhaps, needless stress on the difficulties of the process, and we are not quite disposed to agree with him as to its unsuitability for many purposes which he mentions. Although the exposures he gives may have been necessary by reason of the conditions under which his pictures were produced -namely, the photographing of the objects life size through a ruled screen and by the use of daylight at a time of the year when the light is not very good-it is a very different matter when it is required to produce illustrations for the lantern. In an ordinary studio, the exposure may take from, say, three minutes to a quarter of an hour through the red screen, which of course takes the longest time, while for out-of-door views in bright sunshine, with a moderate aperture of the lens, it is a matter of seconds only. 